\title{
Valorization of desalination brines by electrodialysis with bipolar membranes using nanocomposite anion exchange membranes
}

\author{
Carolina Fernandez-Gonzalez ${ }^{\text {a, b,* }}$, Antonio Dominguez-Ramos ${ }^{a}$, Raquel Ibañez ${ }^{\mathrm{a}}$,
} Yongsheng Chen ${ }^{\mathrm{b}}$, Angel Irabien ${ }^{\mathrm{a}}$

\begin{abstract}
Electrodialysis with bipolar membranes (EDBM) is a promising technology that simultaneously treats and valorizes desalination brines into acids and bases. An important techno-economic challenge of EDBM in this application is the purity of the products, related to the need for more selective ion exchange membranes with good stability working with acids and bases. This work presents the results of the treatment of model desalination brines by EDBM using nanocomposite anion exchange membranes in order to reduce the sulfate content as the main impurity in the acid stack. These membranes are composed by polyethylene, polypropylene, sulfonated poly $(2,6-$ dimethyl-1,4-phenylene oxide) (sPPO) and different loads of $\mathrm{Fe}_{2} \mathrm{O}_{3}-\mathrm{SO}_{4}{ }^{2-}$ nanoparticles. A reduction of the sulfate content in the acid stack was observed when using nanocomposite membranes. The stability of these membranes was evaluated measuring the $\mathrm{Cl}^{-} / \mathrm{SO}_{4}{ }^{2-}$ selectivity after 31,62 and 93 hours of operation. FTIR spectra before and after 93 hours of operation also confirmed the stability of the membranes. The evolution of the main impurities in the acid and the base stacks versus time when applying different current densities is included and related to current efficiency. An estimation of the proton and hydroxyl ions leakages at the different current densities is also presented.
\end{abstract}




\section{Introduction}

Desalination is a competitive alternative, worldwide implemented, for the freshwater supply of countries under water shortages. However, it is associated to both indirect and direct burdens that compromise its sustainability [1]. Indirect environmental burdens are related to greenhouse gases emissions due to the high-energy requirements of desalination technologies. The integration of desalination technologies with renewable power devices is a promising option to overcome this global burden [1-3]. Direct impacts of desalination are associated to the local disposal of desalination brines. The relatively low recovery of conventional desalination technologies (ranging from $50 \%$ to $85 \%$ [4]) causes the generation of high amounts of brines, which content varies depending on the feed water quality, feed water pretreatment, produced water quality and cleaning procedures [5]. This means that per $1 \mathrm{~m}^{3}$ of produced freshwater, a range which goes from $0.3 \mathrm{~m}^{3}$ to $1 \mathrm{~m}^{3}$ of brine are generated. Taking into account the desalination capacity projected for $2015\left(97.5 \cdot 10^{6} \mathrm{~m}^{3} \cdot \mathrm{day}^{-1}\right.$ [6]), the worldwide production of brines could be somewhere between $29.3 \cdot 10^{6} \mathrm{~m}^{3} \cdot$ day $^{-1}$ to $97.5 \cdot 10^{6} \mathrm{~m}^{3} \cdot$ day $^{-}$ ${ }^{1}$ of brine. The most common conventional method for the disposal of brines is seawater discharge, followed by sewer discharge, deep well injections and solar ponds. According to [7] the distribution of these methods for brine disposal is $41 \%, 31 \%, 17 \%$ and $2 \%$ respectively. However, all of these methods present limitations and environmental issues such as high land requirement (evaporation ponds), risk of salt leakages to groundwater (deep well injections and evaporation ponds) and modifications of the receiving media (seawater and sewer discharge). Additionally, it should be taken into account that the disposal of brines into the sewer is only possible for low volumes of brines due to the fact that high quantities affects the performance of the biological treatment at wastewater treatment plants [8]. Thus in the case of high capacity inland desalination plants, the lack of a suitable disposal method can compromise the economic viability of the plant. There is still a need for an innovative solution to avoid the direct environmental impacts associated to the disposal of brines.

Electrodialysis (ED) is a well-known technology for desalination of water [1] that has been reported as an effective approach for the treatment of desalination brines [9-11]. ED allows the concentration of brines with the consequent volume reduction and freshwater generation. Electrodialysis with bipolar membranes (EDBM) is a promising alternative that allows the simultaneous treatment and valorization of desalination brines into acids and bases. The main components of EDBM are anion exchange membranes (AEM), cation exchange membranes (CEM), bipolar membranes (BM) and two electrodes. The electric field generated between the electrodes is the driving force that separates sodium $\left(\mathrm{Na}^{+}\right)$from chloride $\left(\mathrm{Cl}^{-}\right)$through the corresponding CEM and AEM. At the same time this electric field allows the dissociation of water into protons $\left(\mathrm{H}^{+}\right)$and hydroxyl ions $\left(\mathrm{OH}^{-}\right)$in the bipolar membranes. Thus, EDBM simultaneously deals with desalination brines, lowering its salt content, and does valorize this salt into hydrochloric acid and sodium hydroxide. Several works in the literature deals with the modeling [12,13] and laboratory experimental work [14-20] of EDBM for treatment and valorization of brines, mainly focusing on the feasibility and optimization of operation conditions for the treatment. However, there are still some technical and economic challenges to overcome before this approach can develop its full potential. 
A comprehensive summary and discussion of these challenges can be found in our previous work [21]. One of the main techno-economic barriers that we have identified so far is related to the low purity of the products and the need for more selective ion exchange membranes with good stability working with acids and bases. In particular, this barrier is avoided in this work by the use of novel nanocomposite AEM to reduce the content of sulfate $\left(\mathrm{SO}_{4}{ }^{2-}\right)$ in the acid, which is its main impurity [21].

Thus, this work presents the performance of a new nanocomposite commercial based polyethylene AEM in the valorization of desalination brines by EDBM. These membranes, composed mainly by polyethylene, polypropylene, sulfonated poly $(2,6-$ dimethyl-1,4-phenylene oxide) (sPPO) and different loads of $\mathrm{Fe}_{2} \mathrm{O}_{3}-\mathrm{SO}_{4}{ }^{2-}$ nanoparticles $\left(0.2 \% \mathrm{~g} \cdot \mathrm{g}^{-1}\right.$ to $\left.0.6 \% \mathrm{~g} \cdot \mathrm{g}^{-1}\right)$ have a very promising performance in terms of $\mathrm{Cl}^{-} / \mathrm{SO}_{4}{ }^{2-}$ selectivity for desalination of water. In the present work, we state two different hypothesis: i) the developed nanocomposite membranes are suitable for valorization of model desalination brines by EDBM, and ii) its use can improve the quality of the obtained acid. For this purpose, this work presents the results of acid and base generation by EDBM using commercial and nanocomposite AEM as well as commercial cation exchange membranes and bipolar membranes. The influence of $\mathbf{J}$ (80 $\mathrm{A} \cdot \mathrm{m}^{-2}-750 \mathrm{~A} \cdot \mathrm{m}^{-2}$ ) over acid and base production using nanocomposite membranes is presented. Additionally, a discussion of the influence of the current density $(\mathrm{J})$ over the evolution of the concentration of the main impurities of the acid $\left(\mathrm{SO}_{4}{ }^{-2}\right)$ and the base $\left(\mathrm{K}^{+}\right)$is also included and related to the current efficiency $(\eta)$. This is an advance regarding the already published data in the literature that only report the final value of the concentration of impurities [16][19] or just the evolution of one impurity in a compartment [18]. Finally, the stability of nanocomposite membranes working with acids and bases is evaluated by comparison of the Fourier transform infrared spectrum of the nanocomposite membranes before and after 93 hours of operation in EDBM. The evolution of the monovalent selectivity of these membranes before and after three cycles of 31 hour of operation in an EDBM stack is also presented.

\section{Experimental methodology}

\subsection{Membranes}

Nanocomposite membranes synthesized from direct coating of a commercial heterogeneous polyethylene based AEM (AM-PP, Mega, Czech Republic) were used in EDBM experiments for acid and base generation from desalination brines. The coating of the membranes is composed by sulfonated poly (2,6-dimethyl-1,4-phenylene oxide) and functionalized iron oxide nanoparticles. These nanoparticles are commercial iron (III) oxide nanoparticles (Sigma Aldrich, Ø50 nm) that were sulfonated using sulfuric acid obtaining $\mathrm{Fe}_{2} \mathrm{O}_{3}-\mathrm{SO}_{4}{ }^{2-}$. A precise description of the mentioned nanoparticles as well as their sulfonation process can be found elsewere [22,23]. Three different loading of nanoparticles were studied $0.2 \% \mathrm{~g} \cdot \mathrm{g}^{-1}, 0.4 \% \mathrm{~g} \cdot \mathrm{g}^{-1}$ and $0.6 \% \mathrm{~g} \cdot \mathrm{g}^{-1}$ which were named as AM-0.2NP, AM-0.4NP and AM-0.6NP, respectively. Some characteristic of the nanocomposite membranes and the commercial AEM AM-PP are shown in Table 1. Commercial heterogeneous polyethylene based CEM RALEX CM-PP (Mega, Czech Republic) were used for permselectivity and EDBM experiments. Bipolar membranes Fumasep FBM (Fumatech, Germany) were used for EDBM experiments. 
Table 1. Characteristics of the nanocomposite membranes used in this study.

\begin{tabular}{ccccc}
\hline Membrane & $\begin{array}{c}\text { Water contact } \\
\text { angle } \\
\left(^{\left({ }^{[}\right)}\right.\end{array}$ & $\begin{array}{c}\text { Electrical } \\
\text { resistance } \\
\left(\mathbf{\Omega} \cdot \mathbf{c m}^{\mathbf{2}}\right)^{[2]}\end{array}$ & $\begin{array}{c}\text { Limiting J } \\
\left(\mathbf{m A} \cdot \mathbf{c m}^{-2}\right)^{[3]}\end{array}$ & $\begin{array}{c}\text { Permselectivity } \\
\mathbf{S O}_{\mathbf{4}}{ }^{2-} / \mathbf{C l}^{-}\end{array}$ \\
\hline Commercial & 100.1 & 6.3 & 22 & 1.079 \\
AM-PP & 63.7 & 6.1 & 22 & 0.814 \\
AM-0.2NP & 61.6 & 6.1 & 20 & 0.805 \\
AM-0.4NP & 65.8 & 6.4 & 16 & 0.859 \\
AM-0.6NP & & &
\end{tabular}

*For a solution formed by $\mathrm{NaCl} 0.05 \mathrm{~mol} \cdot \mathrm{L}^{-1}$ and $\mathrm{Na}_{2} \mathrm{SO}_{4} 0.05 \mathrm{~mol} \cdot \mathrm{L}^{-1}$

Analytical techniques used for membrane characterization: ${ }^{[1]}$ Water contact angle measurement, ${ }^{[2]}$ Electrochemical impedance spectroscopy and ${ }^{[3]}$ Chronopotentiometry.

\subsection{Acid and base generation by EDMB}

EDBM experiments were performed in a bench scale laboratory electrodialysis system (PCCell, Germany). A commercial electrodialysis cell with two electrodes of $100 \mathrm{~cm}^{2}$ of effective area each, made of titanium and coated with ruthenium oxide were used. Anion and cation exchange membranes were stacked according to Figure 1 (CEM, AEM, BP, CEM, CEM). Nanocomposite AEM were set with the negative layer facing the brine compartment. $\mathrm{J}$ was applied at different levels: $80 \mathrm{~A} \cdot \mathrm{m}^{-2}, 120 \mathrm{~A} \cdot \mathrm{m}^{-2}, 250 \mathrm{~A} \cdot \mathrm{m}^{-}$ ${ }^{2}, 500 \mathrm{~A} \cdot \mathrm{m}^{-2}$ and $750 \mathrm{~A} \cdot \mathrm{m}^{-2}$ by means of a power supply in order to cover the range commonly used in the literature. The temperature was set to approximately $20{ }^{\circ} \mathrm{C}$ using a refrigeration bath. The flow rate was $60 \mathrm{~L} \cdot \mathrm{h}^{-1}$ for each compartment. Synthetic brines that simulate the composition of brine from a reverse osmosis desalination plant in operation in Las Aguilas (Spain) (except for calcium and magnesium) were used in EDBM experiments. A brine with the same composition has already been used in a recent study [18], which was: $\mathrm{Na}^{+} 22.9 \mathrm{~g} \cdot \mathrm{L}^{-1} ; \mathrm{K}^{+} 0.730 \mathrm{~g} \cdot \mathrm{L}^{-1} ; \mathrm{Cl}^{-} 32 \mathrm{~g} \cdot \mathrm{L}^{-1} ; \mathrm{SO}_{4}{ }^{2-} 5.27$ $\mathrm{g} \cdot \mathrm{L}^{-1} ; \mathrm{CO}_{3}{ }^{2-} 0.120 \mathrm{~g} \cdot \mathrm{L}^{-1}$, and $\mathrm{HCO}_{3}{ }^{-} 0.170 \mathrm{~g} \cdot \mathrm{L}^{-1}$. Initial solutions for $\mathrm{HCl}$ as acid and $\mathrm{NaOH}$ as base in the corresponding compartments were $0.1 \mathrm{~mol} \cdot \mathrm{L}^{-1}$ in both cases. A solution of $\mathrm{NaOH} 0.5 \mathrm{~mol} \cdot \mathrm{L}^{-1}$ was used in the electrode compartment. Samples were withdrawn on an hourly basis for measurements of $\mathrm{pH}$ and concentration of $\mathrm{Cl}^{-}, \mathrm{SO}_{4}{ }^{2-}$, $\mathrm{Na}^{+}$and $\mathrm{K}^{+}$. Acid and base titration was also performed. 


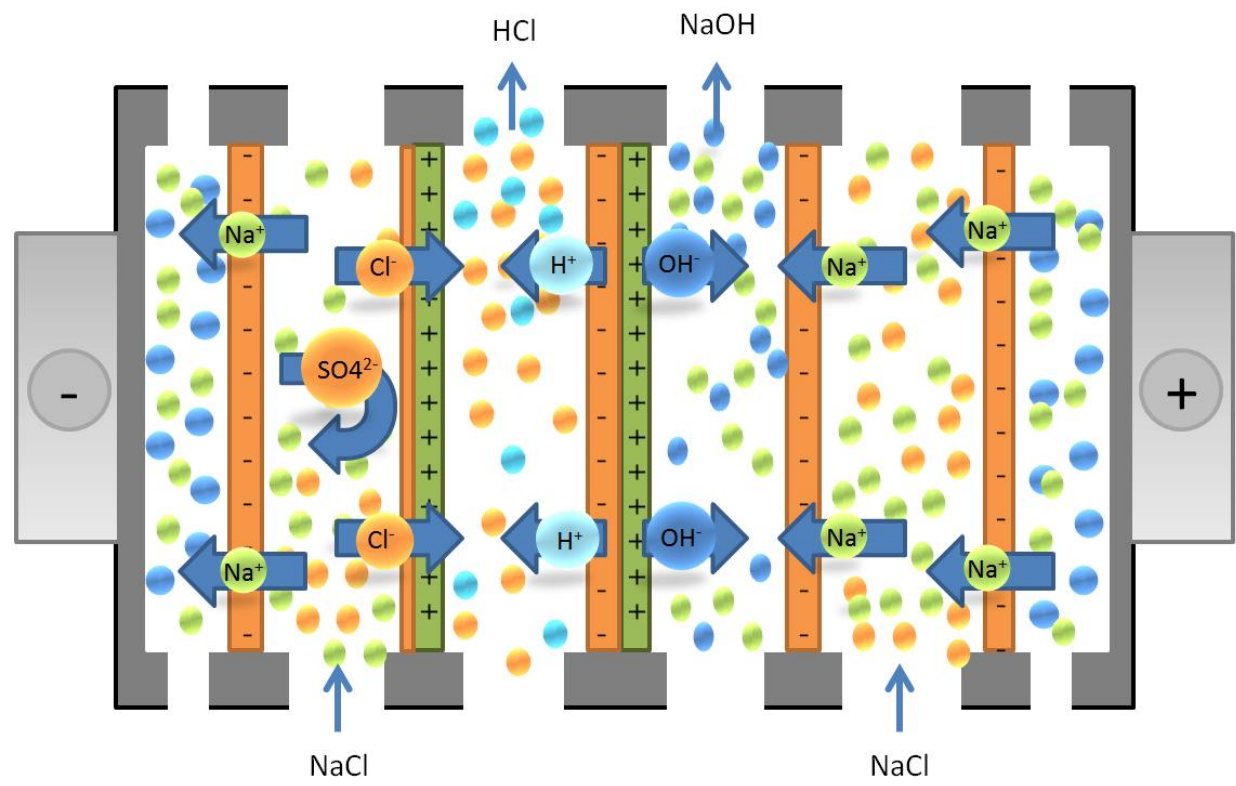

Figure 1. Stack configuration used for EDBM experiments (CEM-AEM-BP-CEMCEM).

\subsection{Permselectivity experiments and stability of nanocomposite membranes}

Permselectivity experiments were performed in the laboratory scale experimental setup and experimental conditions described in the previous section for EDBM experiments, only modifying membrane configuration, solutions and $\mathrm{J}$. The new membrane configuration for permselectivity experiments is shown in Figure 2 (CEM, AEM, $\mathrm{CEM}$ ). The modified surface of the anion exchange membrane was set facing the dilute compartment in order to act as a barrier to $\mathrm{SO}_{4}{ }^{2-}$ ions. Solutions prepared with $\mathrm{NaCl}$ $0.05 \mathrm{~mol} \cdot \mathrm{L}^{-1}$ and $\mathrm{Na}_{2} \mathrm{SO}_{4} 0.05 \mathrm{~mol} \cdot \mathrm{L}^{-1}$ were fed to the dilute and concentrate compartment. A solution of $\mathrm{Na}_{2} \mathrm{SO}_{4} 0.5 \mathrm{~mol} \cdot \mathrm{L}^{-1}$ was used as electrolyte in the electrode compartment. In this case, the $\mathrm{J}$ value was set to $120 \mathrm{~A} \cdot \mathrm{m}^{-2}$, which is the same $\mathrm{J}$ value used for the characterization of the membranes. This value corresponds to the $75 \%$ of the limiting $\mathbf{J}$ of the nanocomposite membrane with lower limiting $\mathbf{J}$ (see Table 1).

The evaluation of the anion monoselectivity of the membranes was performed using the transport numbers for $\mathrm{SO}_{4}{ }^{-2}$ and $\mathrm{Cl}^{-}$in the dilute compartment. The transport number for a specific ion $\left(\mathrm{t}_{\mathrm{A}}\right)$ can be defined as the ratio between the flux of that ion $\left(\mathrm{J}_{\mathrm{A} 1}\right)$ and the total flux of ions $\left(\mathrm{J}_{\mathrm{T}}\right)$ :

$t_{A}=\frac{J_{A 1}}{J_{T}}$

Eq. 1

To evaluate the relative permselectivity of the membranes between different ions and avoid the mole fraction effect [24] the transport number ratio is defined in [25] as:

$P_{A 2 / A 1}=\frac{t_{A 2} / t_{A 1}}{C_{A 2} / C_{A 1}}=\frac{J_{A 2} / J_{A 1}}{C_{A 2} / C_{A 1}}$

Eq. 2

Where $t_{\mathrm{A} 2}$ and $t_{\mathrm{A} 1}$ are the transport numbers of ions $\mathrm{A} 2$ and $\mathrm{A} 1 . \mathrm{C}_{\mathrm{A} 2}$ and $\mathrm{C}_{\mathrm{A} 1}$ are the average concentration of ions $\mathrm{A} 2$ and $\mathrm{A} 1$ during the $\mathrm{ED}$ experiment in the dilute 
compartment. In this work, $\mathrm{A} 1$ corresponds to $\mathrm{Cl}^{-}$and $\mathrm{A} 2$ to $\mathrm{SO}_{4}{ }^{2-}$, thus the lower the $\mathrm{P}_{\mathrm{A} 2 / \mathrm{A} 1}$, the higher the monovalent selectivity of the membrane. Fluxes of $\mathrm{Cl}^{-}, \mathrm{SO}_{4}{ }^{2-}$ and $\mathrm{Na}^{+}$were calculated from the evolution of the concentration of the different ions in the dilute compartment.

To evaluate the stability of the negatively charged layer on the surface of the anion exchange membrane, permselectivity tests were performed just in one of the three modified membranes. The selection of the membrane AM-0.4NP over the two other membranes was done because AM-0.4NP has the best set of properties from Table 1: lowest water angle contact, tied for lowest electrical resistance and highest monovalent permselectivity. Consequently, the membrane AM-0.4NP was tested after 3 cycles of EDBM experiments. Each cycle of experiments corresponds to one experiment at the five different current densities selected in this work $\left(80 \mathrm{~A} \cdot \mathrm{m}^{-2}, 120 \mathrm{~A} \cdot \mathrm{m}^{-2}, 250 \mathrm{~A} \cdot \mathrm{m}^{-2}\right.$, $500 \mathrm{~A} \cdot \mathrm{m}^{-2}$ and $750 \mathrm{~A} \cdot \mathrm{m}^{-2}$ ). This is translated to 15 experiments in EDBM with the membrane AM-0.4NP and a total operation time of 93 hours. The results were compared with the original permselectivity of the membranes before EDBM experiments.

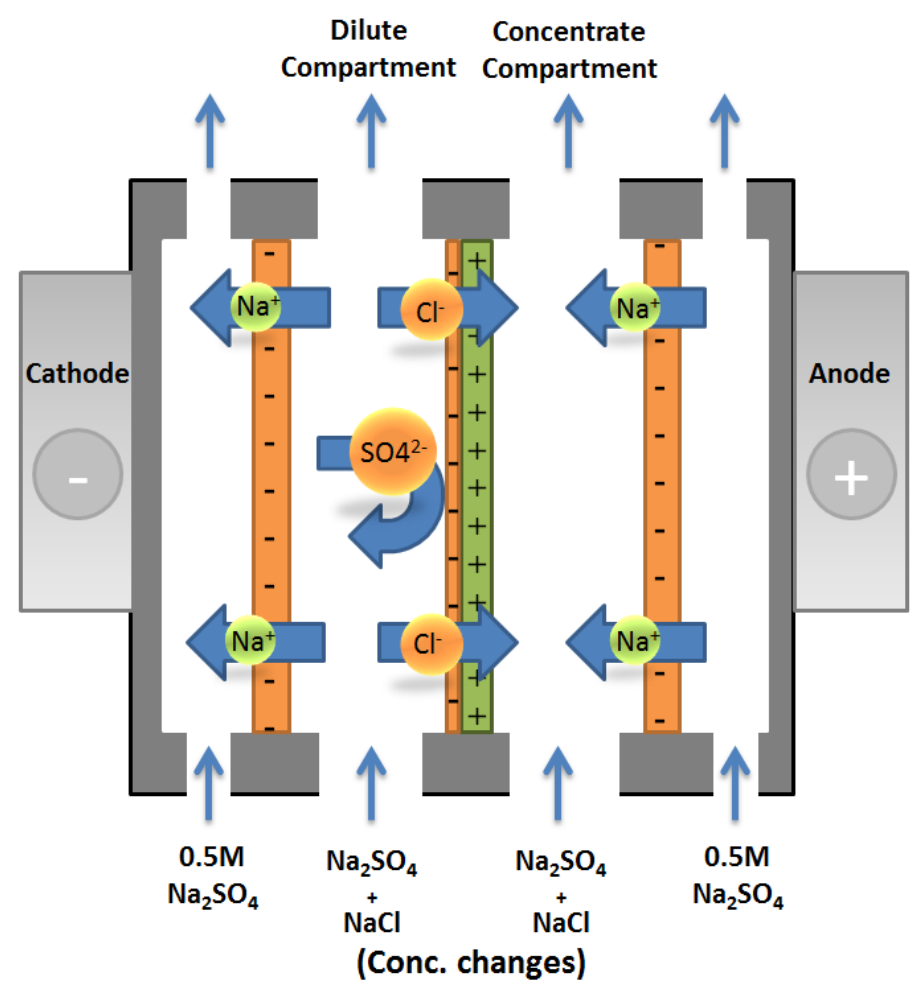

Figure 2. Stack configuration used for permselectivity experiments (CEM-AEM-CEM).

\subsection{Analytical methods}

\subsubsection{Ion chromatography}

Concentrations of $\mathrm{Cl}^{-}, \mathrm{SO}_{4}{ }^{2-}, \mathrm{Na}^{+}$and $\mathrm{K}^{+}$were measured by ion chromatography (Dionex ICIS-1100 for anions and Dionex DX-120 for cations, Dionex Corp., USA). Acid and base concentrations were determined by acid-base titration using analytical grade reagents. 


\subsubsection{FTIR spectra analysis}

The chemical composition of the membranes before and after 93 hours of operation in EDBM was determined by Fourier transform infrared spectroscopy (FTIR) (Spectrum 65, Perkin Elmer, Waltham, MA, US). Spectra were scanned in a range of $650-4000 \mathrm{~cm}^{-}$

1 . For each sample, the scan was repeated 10 times. Results were corrected using a spectrum of ambient air as a background.

\subsection{Data analysis}

Current efficiency $(\eta)$ for a specific specie is a critical important parameter to evaluate EDBM viability as it determines the fraction of the applied current that is effectively converted [18]. Therefore $\eta$ was calculated according to Eq. 3:

$\eta=\frac{\left(C_{t}-C_{0}\right) \cdot V \cdot F}{N \cdot I \cdot t}$

Eq. 3

Where $\mathrm{C}_{0}$ and $\mathrm{C}_{\mathrm{t}}$ are the initial concentration and the concentration of the acid and base at any time operation time $\mathrm{t}, \mathrm{V}$ is the volume circulated in each compartment, $\mathrm{F}$ is the Faraday constant, $\mathrm{N}$ is the number of cell triplets, and I is the total applied current in the cell. Eq. 3 was also used to determine the amount of electric current used for transport of impurities to the acid and the base stack.

\section{Results and discussion}

\subsection{Acid generation using commercial and nanocomposite membranes}

EDBM experiments were performed using commercial and nanocomposite AEM to evaluate the increase in products purity by using nanocomposite membranes. A $\mathrm{J}$ value of $120 \mathrm{~A} \cdot \mathrm{m}^{-2}$ was selected for these experiments as it was also used for the characterization of the monovalent selectivity of the AEM. According to the characteristics of the AEM used in this work (see Table 1), all the nanocomposite membranes (AM-0.2NP, AM-0.4NP and AM-0.6NP) are less selective to $\mathrm{SO}_{4}{ }^{2-}$ than the commercial membrane, being the best membrane AM- $0.4 \mathrm{NP}$ with a $34 \%$ lower $P_{A 2 / A 1}$ than the commercial membrane. The reason behind the monovalent selectivity of the nanocomposite membranes is that the layer of $\mathrm{sPPO}$ and $\mathrm{Fe}_{2} \mathrm{O}_{3}-\mathrm{SO}_{4}{ }^{2-}$ nanoparticles confers a negative charge to the surface of AEM. This negative charge causes electrostatic repulsions between anions and the negative surface of the AEM. These repulsions are larger for multivalent ions such as $\mathrm{SO}_{4}{ }^{2-}$ than for monovalent ions such as $\mathrm{Cl}^{-}$[26], so the layer confers monovalent selectivity to the AEM. Nanocomposite membranes are expected to lead to a lower $\mathrm{SO}_{4}{ }^{2-}$ content in the acid stack. From Figure 3 it can be seen that the final $\mathrm{SO}_{4}{ }^{2-}$ content in the acid stack is just around $10 \%$ lower when using nanocomposite membranes and there is not a statistical significant difference among the nanocomposite membranes with different loadings of functionalized iron oxide nanoparticles . To further explain this drop in the $\mathrm{SO}_{4}{ }^{2-}$ concentration, Table 2 includes the $\mathrm{SO}_{4}{ }^{2-}$ flux in the acid stack for nanocomposite and commercial membranes, where it can be observed that the use of nanocomposite membranes can diminish the $\mathrm{SO}_{4}{ }^{2-}$ flux from $9 \%$ to $15 \%$ in the acid stack when 
compared to commercial membranes. However, the improvement in acid quality is

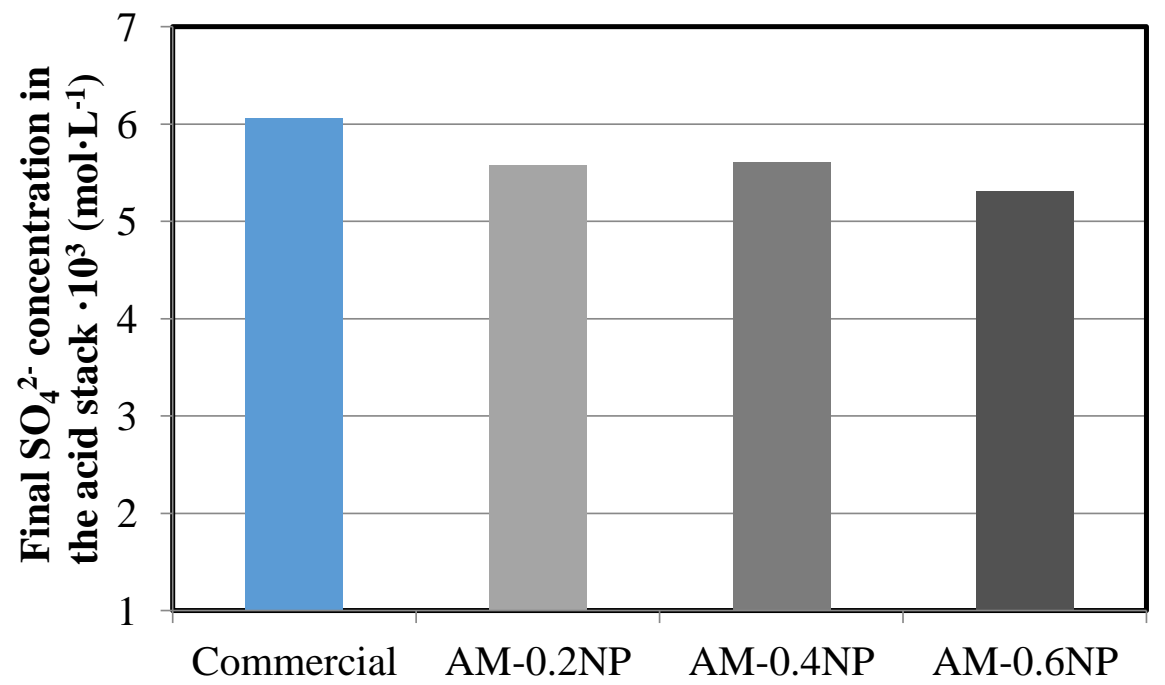

Figure 3. Final $\mathrm{SO}_{4}{ }^{2-}$ concentration in the acid stack using commercial and nanocomposite AEM after applying $\mathrm{J}=120 \mathrm{~A} \cdot \mathrm{m}^{-2}$. 


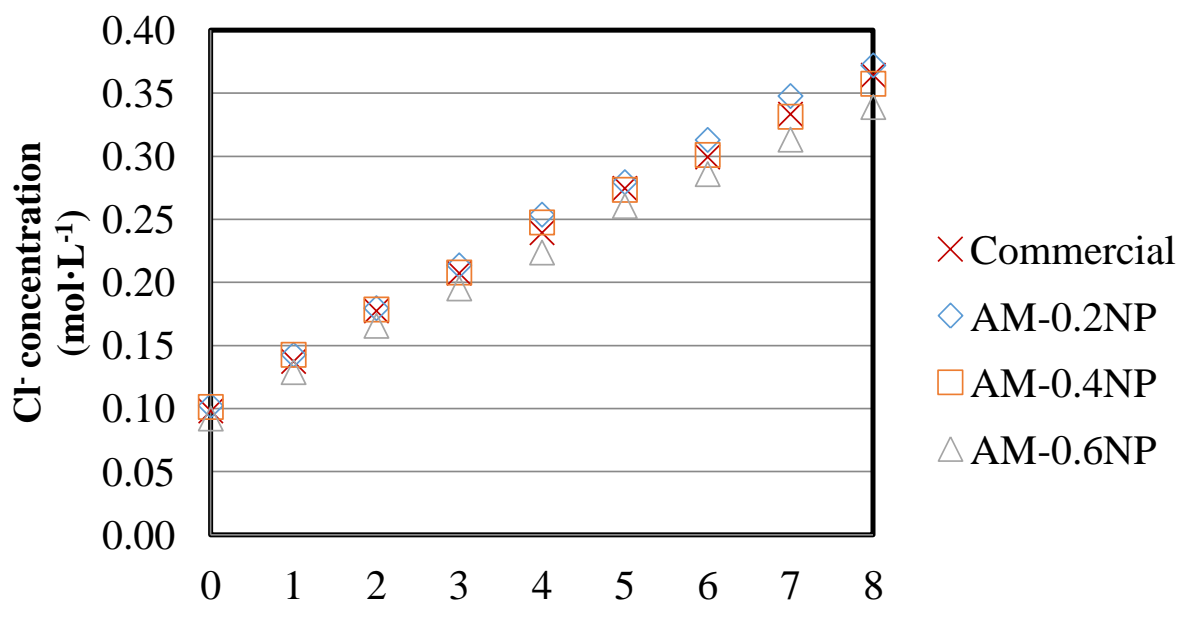

Time (h)

Figure 4. Evolution of $\mathrm{Cl}^{-}$concentration in the acid stack using commercial and nanocomposite AEM after applying $\mathrm{J}=120 \mathrm{~A} \cdot \mathrm{m}^{-2}$.

Table 2. Summary of the $\mathrm{SO}_{4}{ }^{2-}$ flux in the acid stack using commercial and nanocomposite AEM.

\begin{tabular}{cccc}
\hline Membrane & $\begin{array}{c}\left(\mathbf{S O}_{4}^{-2} \text { Flux }\right) \cdot \mathbf{1 0}^{\mathbf{2}} \\
\left(\mathrm{mol} \cdot \mathrm{h}^{-1} \cdot \mathrm{m}^{-2}\right)\end{array}$ & $\mathbf{R}^{\mathbf{2}}$ & $\begin{array}{c}\text { Decrease } \\
(\%)\end{array}$ \\
\cline { 1 - 3 } Commercial AM-PP & 7.36 & 0.993 & - \\
AM-0.2NP & 6.52 & 0.990 & 12 \\
AM-0.4NP & 6.73 & 0.988 & 9 \\
AM-0.6NP & 6.24 & 0.992 & 15 \\
\hline
\end{tabular}

\subsubsection{Influence of current density over acid production, main impurities and current efficiency using nanocomposite membranes}

In order to evaluate the influence of $\mathrm{J}$ over the acid production and the content of impurities in the acid stack, experiments were performed at current densities from 80 $\mathrm{A} \cdot \mathrm{m}^{-2}$ to $750 \mathrm{~A} \cdot \mathrm{m}^{-2}$. The $\mathrm{SO}_{4}{ }^{2-}$ and $\mathrm{Cl}^{-}$concentration increased linearly versus time for the different studied current densities. As the evolution is linear, the $\mathrm{SO}_{4}{ }^{2-}$ and $\mathrm{Cl}^{-}$fluxes from the brine stack to the acid stack can be straightforwardly fitted from the slope. This calculation allows the comparison of the performance of the different membranes and in this case, the different nanocomposite membranes AM-0.2NP, AM-0.4NP and AM$0.6 \mathrm{NP}$. A complete summary of $\mathrm{SO}_{4}{ }^{2-}$ and $\mathrm{Cl}^{-}$fluxes for the different current densities using different nanocomposite membranes is included in Table 3 and Table 4 respectively. The linear behavior of $\mathrm{SO}_{4}{ }^{2-}$ and $\mathrm{Cl}^{-}$concentration versus time is supported by the goodness of the fitting presented in Table 3 and Table $4\left(\mathrm{R}^{2}\right.$ around 0.99$)$. The performance of the nanocomposite membranes in terms of $\mathrm{SO}_{4}{ }^{2-}$ and $\mathrm{Cl}^{-}$fluxes is very similar in the present experimental conditions as displayed in Table 3 and Table 4. Thus 
the membrane with more promising characteristics, AM-0.4NP, will be chosen for stability tests as reference membrane. The evolution of the concentration of $\mathrm{H}^{+}, \mathrm{SO}_{4}{ }^{2-}$ and $\mathrm{Cl}^{-}$at different current densities when using the membrane AM-0.4NP is presented in Figure 5.

From Figure 5 a) and Figure $5 \mathrm{~b}$ ), it can be concluded that the production of $\mathrm{HCl}$ is highly dependent on the $\mathrm{J}$ showing that the higher the applied $\mathrm{J}$, the better the production rate. Similar trends has been reported previously in acid and base generation from desalination brines [16][18][19]. The rise in acid concentration at the different current densities matches well with the drop in the $\mathrm{Cl}^{-}$concentration in the brine stack (as shown in Figure 6).

To further analyze the influence of $\mathrm{J}$ in acid generation, $\mathrm{Cl}^{-}$and $\mathrm{SO}_{4}{ }^{2-}$ fluxes of the AM$0.4 \mathrm{NP}$ membrane were plotted against $\mathrm{J}$ in Figure 7 . Once again, the evolution of the fluxes with $J$ can be properly fitted to a linear relationship ( $\mathrm{R}^{2}$ over 0.99$)$. This is due to the high concentration of $\mathrm{Cl}^{-}$and $\mathrm{SO}_{4}{ }^{2-}$ in the brine, which avoid mass transport limitations between the dilute compartment and the acid stack. The ionic flux that occurs in EDBM is a combination of migration due to the electric field and diffusion due to the difference of concentrations between stacks. A previous study [13] reported that the contribution of the diffusion to the total ion flux depends on the difference of concentration between the concentrated stack and the dilute stack (brine and acid in the present study respectively). It was reported that it can account up to a $25 \%$ of the ionic flux when working at relatively high current densities $\left(250 \mathrm{~A} \cdot \mathrm{m}^{-2}-1000 \mathrm{~A} \cdot \mathrm{m}^{-2}\right)$ being the difference of concentration between stacks around $2 \mathrm{~mol} \cdot \mathrm{L}^{-1}$. The contribution of ionic flux due to diffusion to the total ionic flux increase as the current density decrease thus becomes the ionic flux contribution at no current density, thus the fitness has no zero intercept. In the case of $\mathrm{Cl}^{-}$, the mathematical linear relationship is simply given by $F_{C l^{-}}=a_{C l^{-}} J+b_{C l^{-}}$being $F_{C l^{-}}$the $\mathrm{Cl}^{-}$flux and the fitting parameters for $\mathrm{Cl}^{-} a_{C l^{-}}=0.02$ $\mathrm{mol} \cdot \mathrm{h}^{-1} \cdot \mathrm{A}^{-1}$ and $b_{C l^{-}}=0.83 \mathrm{~mol} \cdot \mathrm{h}^{-1} \cdot \mathrm{m}^{-2}$. This means that the increase of $\mathrm{Cl}^{-}$flux is favored by incrementing the $\mathrm{J}$ value. Necessarily, a decrease in $\eta$ is noticed when enlarging $\mathrm{J}$. The difference between the raising of the $\mathrm{J}$ value and the increase of $\mathrm{Cl}^{-}$ flux is more significant at low $\mathbf{J}$ values than at high $\mathbf{J}$ values, as the parameter that is not influenced by $\mathrm{J}$ related to diffusion phenomena, $b_{\mathrm{Cl}^{-}}$, lose importance in the total $\mathrm{Cl}^{-}$ flux at high fluxes. This explains the decrease in $\eta$ when increasing $\mathbf{J}$ as observed in Figure $8 \mathrm{a}$ ), which is more pronounced at low $\mathbf{J}$ and very small as $\mathbf{J}$ goes up.

The $\mathrm{H}^{+}$leakage has been reported to have a pronounced influence in EDBM process [15]. This leakage can explain the decrease of $\eta$ versus time observed in Figure $8 \mathrm{~b}$ ). A decrease of $\eta$ with conversion of $\mathrm{NaCl}$ into $\mathrm{HCl}$ has also been reported recently [19]. For further discussion and understanding the reasons behind how the applied current is used in the EDBM at the different $\mathrm{J}$ values, Table 5 includes the relative contribution of current used in the transport of the most important ions in the acid stack $\left(\mathrm{Na}^{+}, \mathrm{Cl}^{-}\right.$and $\mathrm{SO}_{4}{ }^{2-}$ ) as a percentage (other ions add up to $100 \%$ ). Thanks to Table 5 it can be observed that the utilization of current for $\mathrm{SO}_{4}{ }^{2-}$ transport increase when $\mathrm{J}$ does. In the case of $\mathrm{SO}_{4}{ }^{2-}$, the mathematical relationship is also linear: $F_{\mathrm{SO}_{4}^{2-}}=a_{\mathrm{SO}_{4}^{2-}} \mathrm{J}+b_{\mathrm{SO}_{4}^{2-}}$ being $F_{S_{4}^{2-}}$ the $\mathrm{SO}_{4}{ }^{2-}$ flux and the fitting parameters $a_{S O_{4}^{2-}}=8.45 \cdot 10^{-4} \mathrm{~mol} \cdot \mathrm{h}^{-1} \cdot \mathrm{A}^{-1}$ and $b_{\mathrm{SO}_{4}^{2-}}=-2.84 \cdot 10^{-2} \mathrm{~mol} \cdot \mathrm{h}^{-1} \cdot \mathrm{m}^{-2}$. Similarly to the case of $\mathrm{Cl}^{-}$, this difference becomes less important with increasing $\mathrm{J}$. Thus, low current densities will allow lower $\mathrm{SO}_{4}{ }^{2-}$ content in the product. Final concentrations of $\mathrm{Na}^{+}$in the acid stack at the different current 
densities varied from $2.1 \cdot 10^{-3} \mathrm{~mol} \cdot \mathrm{L}^{-1}$ to $12.6 \cdot 10^{-3} \mathrm{~mol} \cdot \mathrm{L}^{-1}$. Taking into account that Table 5 includes the $\eta$ value of the main ions of the acid stack, and the presence of $\mathrm{CO}_{3}{ }^{2-}$ and $\mathrm{HCO}_{3}{ }^{-}$is very low in the brine $\left(120 \mathrm{mg} \cdot \mathrm{L}^{-1}\right.$ and $170 \mathrm{mg} \cdot \mathrm{L}^{-1}$ respectively), the $\mathrm{H}^{+}$leakage can be estimated from $8 \%$ at $80 \mathrm{~A} \cdot \mathrm{m}^{2}$ to $35 \%$ at $750 \mathrm{~A} \cdot \mathrm{m}^{2}$. A larger $\mathrm{H}^{+}$ leakage due to $\mathrm{J}$ has already been reported in the literature [32]. The results of $\eta$ reported in this work for acid production (Figure 8 a) and Table 5) are very similar to the previously reported in the literature for valorization of desalination brines, namely $70-77 \%$ for $15-25 \mathrm{~V}$ [15], $70-45 \%$ for $200-1,000 \mathrm{~A} \cdot \mathrm{m}^{-2}$ [18], and $51-55 \%$ for $340-$ $570 \mathrm{~A} \cdot \mathrm{m}^{-2}[19]$. 


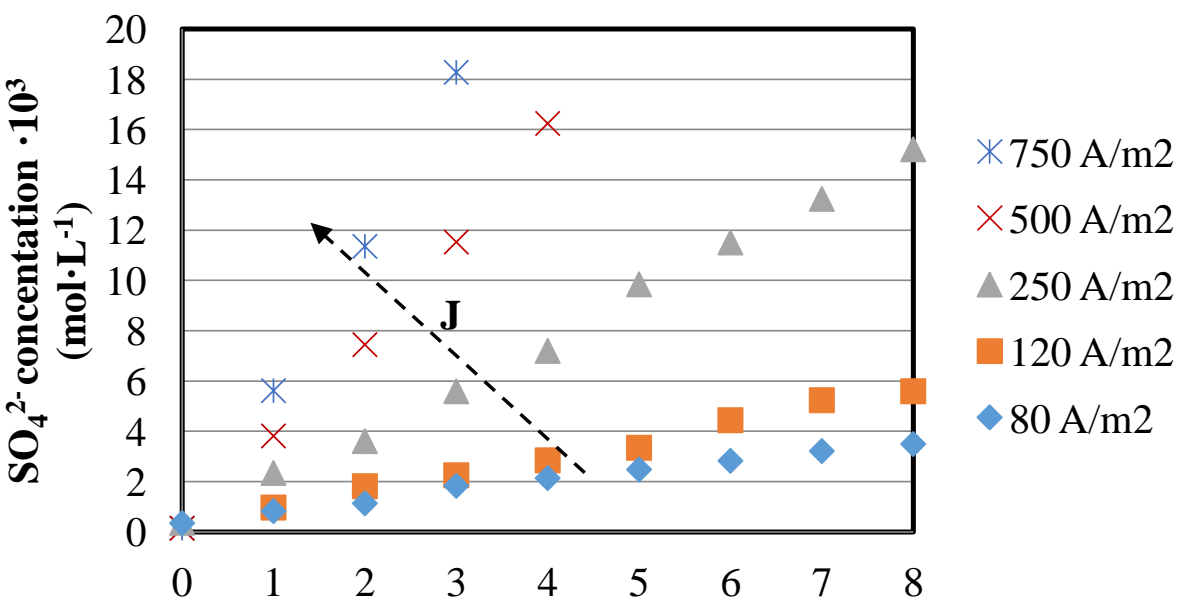

Time (h)

Figure 5. Evolution of the concentration of a) $\mathrm{Cl}^{-}$b) $\mathrm{H}^{+}$and c) $\mathrm{SO}_{4}{ }^{2-}$ in the acid stack at different current densities using the membrane AM-0.4NP. 
Table 3. $\mathrm{Cl}^{-}$flux for the different current densities and nanocomposite membranes used in this study.

\begin{tabular}{|c|c|c|c|c|c|c|c|c|c|c|}
\hline \multirow[b]{3}{*}{ Membrane } & \multicolumn{10}{|c|}{$\mathbf{J}\left(\mathbf{A} \cdot \mathbf{m}^{-2}\right)$} \\
\hline & \multicolumn{2}{|l|}{80} & \multicolumn{2}{|l|}{120} & \multicolumn{2}{|l|}{250} & \multicolumn{2}{|l|}{500} & \multicolumn{2}{|l|}{750} \\
\hline & $\begin{array}{c}F_{C l^{-}} \\
\left(\mathbf{m o l} \cdot \mathbf{h}^{-1} \cdot \mathbf{m}^{-2}\right)\end{array}$ & $\mathbf{R}^{2}$ & $\begin{array}{c}F_{C l^{-}} \\
\left(\mathbf{m o l} \cdot \mathbf{h}^{-1} \cdot \mathbf{m}^{-2}\right)\end{array}$ & $\mathbf{R}^{2}$ & $\begin{array}{c}F_{C l^{-}} \\
\left(\mathbf{m o l} \cdot \mathbf{h}^{-1} \cdot \mathbf{m}^{-2}\right)\end{array}$ & $\mathbf{R}^{2}$ & $\begin{array}{c}F_{C l^{-}} \\
\left(\mathrm{mol}^{-1} \mathbf{h}^{-1} \cdot \mathbf{m}^{-2}\right)\end{array}$ & $\mathbf{R}^{2}$ & $\begin{array}{c}F_{C l^{-}} \\
\left(\mathrm{mol}^{\cdot} \mathbf{h}^{-1} \cdot \mathbf{m}^{-2}\right)\end{array}$ & $\mathbf{R}^{2}$ \\
\hline AM-0.2 NP & 2.2 & 0.998 & 3.3 & 0.996 & 5.8 & 0.993 & 12.1 & 0.995 & 16.5 & 0.993 \\
\hline AM-0.4 NP & 2.5 & 0.997 & 3.1 & 0.995 & 5.7 & 0.992 & 11.9 & 0.993 & 15.7 & 0.996 \\
\hline AM-0.6 NP & 2.5 & 0.996 & 3.0 & 0.996 & 5.3 & 0.997 & 11.3 & 0.996 & 16.0 & 0.992 \\
\hline
\end{tabular}

Table 4. $\mathrm{SO}_{4}{ }^{2-}$ flux for the different current densities and nanocomposite membranes used in this study.

\begin{tabular}{|c|c|c|c|c|c|c|c|c|c|c|}
\hline \multirow[b]{3}{*}{ Membrane } & \multicolumn{10}{|c|}{$J\left(A \cdot m^{-2}\right)$} \\
\hline & \multicolumn{2}{|l|}{80} & \multicolumn{2}{|l|}{120} & \multicolumn{2}{|l|}{250} & \multicolumn{2}{|l|}{500} & \multicolumn{2}{|l|}{750} \\
\hline & $\begin{array}{c}F_{S O_{4}^{2-}} \\
\left(\mathrm{mol} \cdot \mathrm{h}^{-1} \cdot \mathrm{m}^{-2}\right)\end{array}$ & $\mathrm{R}^{2}$ & $\begin{array}{c}F_{S O_{4}^{2-}} \\
\left(\mathrm{mol} \cdot \mathrm{h}^{-1} \cdot \mathrm{m}^{-2}\right)\end{array}$ & $\mathrm{R}^{2}$ & $\begin{array}{c}F_{S O_{4-2-}^{2-}} \\
\left(\mathrm{mol} \cdot \mathrm{h}^{-1} \cdot \mathrm{m}^{-2}\right)\end{array}$ & $\mathrm{R}^{2}$ & $\begin{array}{c}F_{S O_{4}^{2-}} \\
\left(\mathrm{mol} \cdot \mathrm{h}^{-1} \cdot \mathrm{m}^{-2}\right)\end{array}$ & $\mathrm{R}^{2}$ & $\begin{array}{c}F_{S O_{4}^{2-}} \\
\left(\mathrm{mol} \cdot \mathrm{h}^{-1} \cdot \mathrm{m}^{-2}\right)\end{array}$ & $\mathrm{R}^{2}$ \\
\hline AM-0.2 NP & 0.033 & 0.992 & 0.065 & 0.989 & 0.178 & 0.997 & 0.403 & 0.987 & 0.607 & 0.995 \\
\hline AM-0.4 NP & 0.040 & 0.990 & 0.067 & 0.988 & 0.187 & 0.997 & 0.399 & 0.996 & 0.601 & 0.996 \\
\hline AM-0.6 NP & 0.042 & 0.994 & 0.062 & 0.991 & 0.162 & 0.994 & 0.406 & 0.998 & 0.610 & 0.998 \\
\hline
\end{tabular}




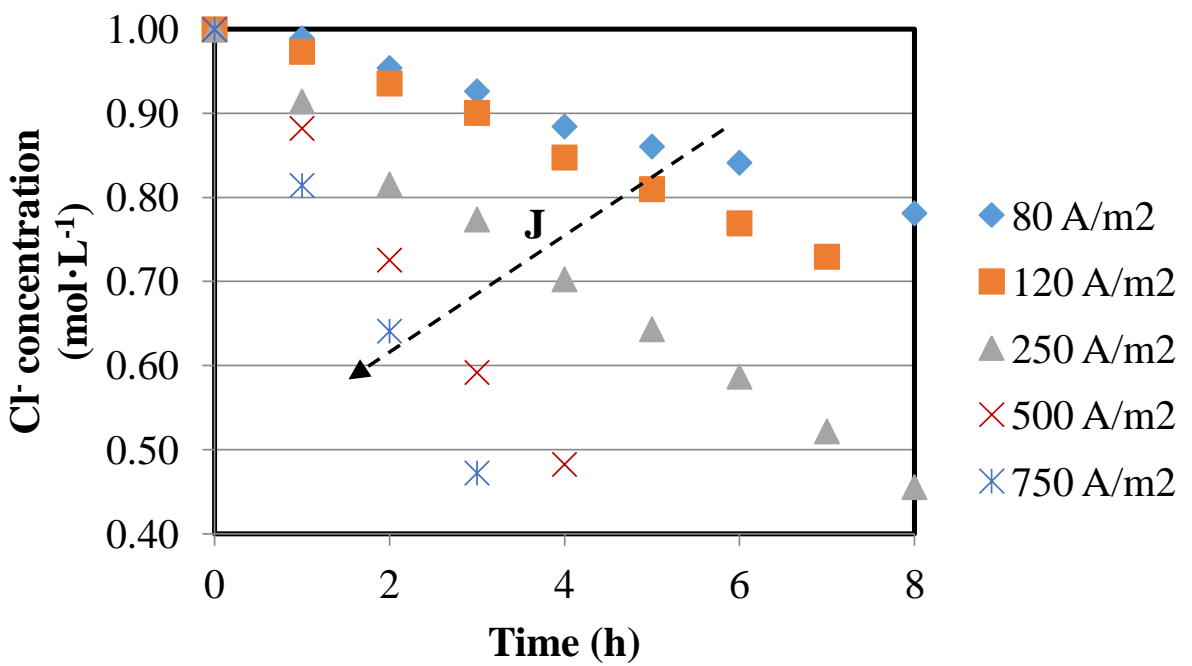

Figure 6. Evolution of concentration of $\mathrm{Cl}^{-}$in the brine stack at different current densities using nanocomposite membranes AM-0.4NP.
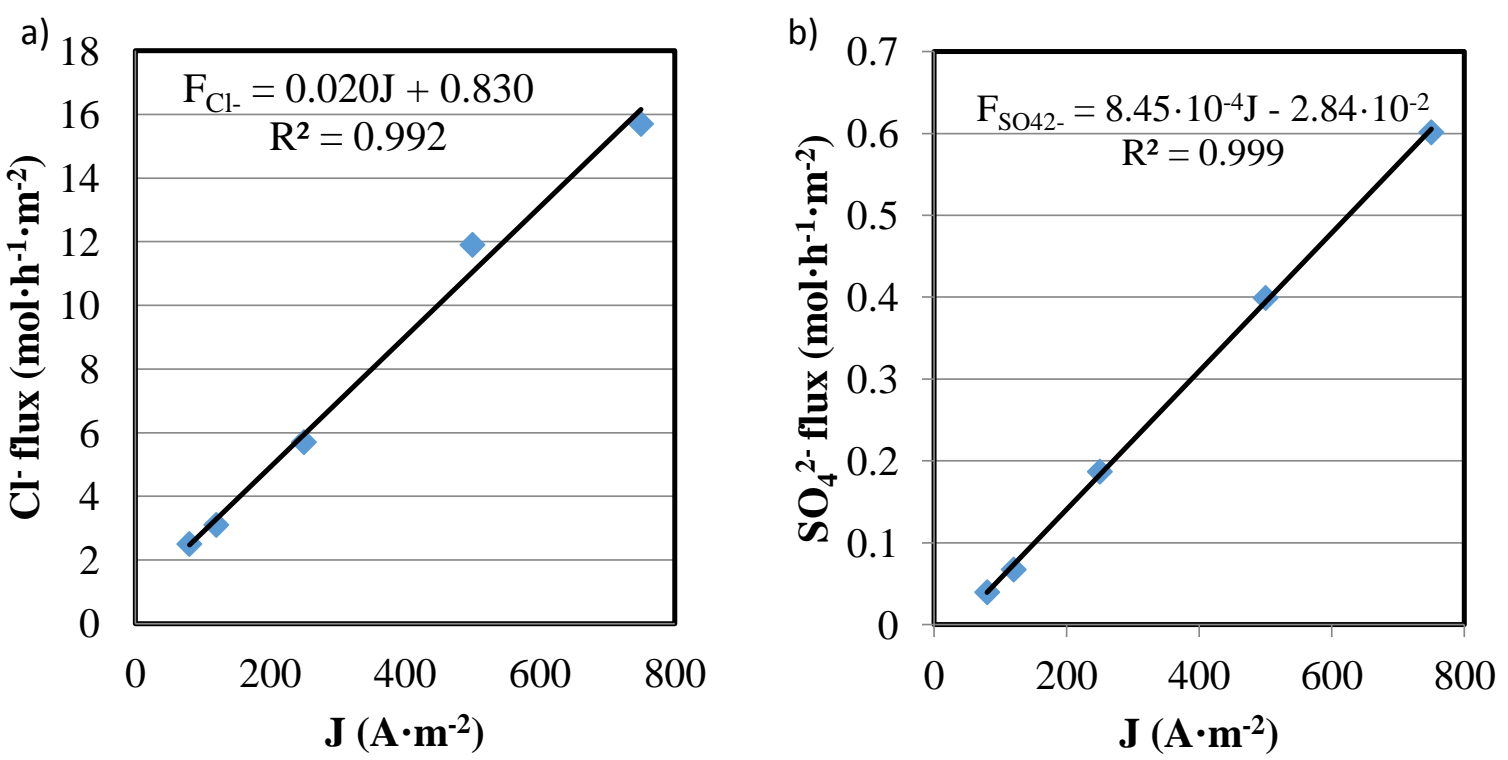

Figure 7. Evolution of the $\mathrm{F}$ of a) $\mathrm{Cl}^{-}$and b) $\mathrm{SO}_{4}{ }^{2-}$ versus $\mathrm{J}$ using the nanocomposite AM-0.4NP. 
a)

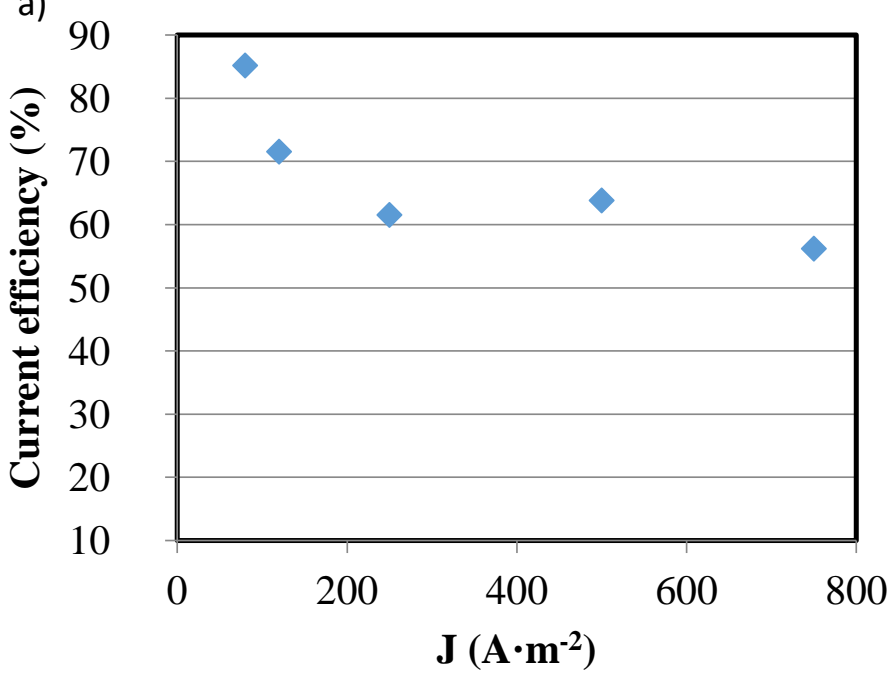

b)

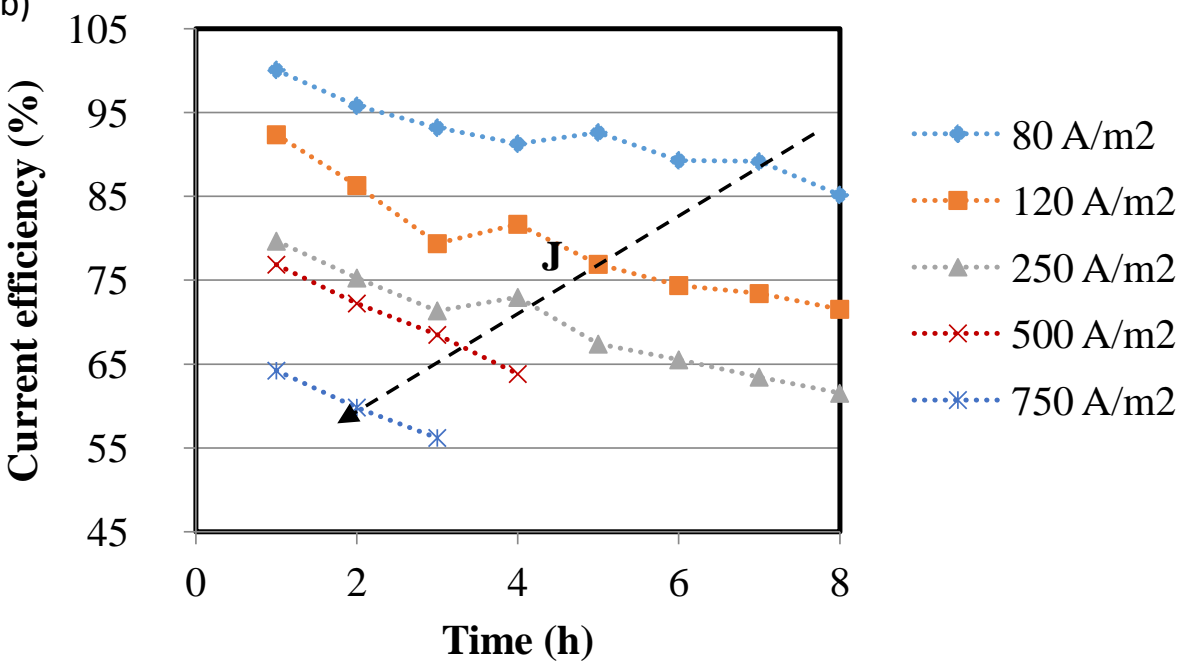

Figure 8. Evolution of $\eta$ with a) time and b) $\mathrm{J}$ in the acid stack using the membrane AM-0.4NP.

Table 5. Fraction of the $\eta$ for the transport of different ions at different $\mathbf{J}$ values in the acid stack using the nanocomposite AM-0.4NP. Results expressed as percentage by means of Eq. 3.

\begin{tabular}{ccccc}
\hline \multicolumn{5}{c}{$\boldsymbol{\eta}$} \\
\hline $\begin{array}{c}\mathbf{J} \\
\left(\mathbf{A} \cdot \mathbf{m}^{-2}\right)\end{array}$ & $\begin{array}{c}\mathbf{C l}^{-} \\
(\boldsymbol{\%})\end{array}$ & $\begin{array}{c}\mathbf{S O}_{\mathbf{4}}{ }^{2-} \\
(\boldsymbol{\%})\end{array}$ & $\begin{array}{c}\mathbf{N a}^{+} \\
(\boldsymbol{\%})\end{array}$ & $\begin{array}{c}\text { Total } \\
(\boldsymbol{\%})\end{array}$ \\
\hline $\mathbf{8 0}$ & 85.18 & 5.50 & 1.75 & 92.43 \\
$\mathbf{1 2 0}$ & 71.55 & 6.16 & 0.47 & 78.18 \\
$\mathbf{2 5 0}$ & 61.53 & 8.31 & 1.50 & 71.34 \\
$\mathbf{5 0 0}$ & 63.82 & 9.00 & 0.22 & 73.05 \\
$\mathbf{7 5 0}$ & 56.20 & 9.02 & 0.19 & 65.40 \\
\hline
\end{tabular}




\subsection{Base generation using commercial membranes. Influence of current density over base production, main impurities and current efficiency.}

The evolution of the $\mathrm{Na}^{+}, \mathrm{OH}^{-}$and $\mathrm{K}^{+}$concentration in the base stack for different $\mathrm{J}$ values using commercial membranes is presented in Figure S1. Similarly to acid production, the evolution of the ions is linear versus time and the production rate is also faster when increasing the $\mathrm{J}$ values. This allows the calculation $\mathrm{Na}^{+}$and $\mathrm{K}^{+}$fluxes at different $\mathbf{J}$ values. As expected, the increase of $\mathrm{Na}^{+}$concentration in the base stack (Figure S1) matches with the decrease of $\mathrm{Na}^{+}$concentrationin the brines compartment (Figure S2).

After plotting the $\mathrm{Na}^{+}$and $\mathrm{K}^{+}$fluxes versus $\mathrm{J}$, once again a linear relationship is obtained (Figure 9). In this case, the same trend is observed for both ions thus $a_{N a^{+}}=0.041$ $\mathrm{mol} \cdot \mathrm{h}^{-1} \cdot \mathrm{A}^{-1} ; b_{N a^{+}}=2.973 \mathrm{~mol} \cdot \mathrm{h}^{-1} \cdot \mathrm{m}^{-2} ; a_{K^{+}}=1.07 \cdot 10^{-3} \mathrm{~mol} \cdot \mathrm{h}^{-1} \cdot \mathrm{A}^{-1}$; and $b_{K^{+}}=7.63 \cdot 10^{-2}$ $\mathrm{mol} \cdot \mathrm{h}^{-1} \cdot \mathrm{m}^{-2}$. Similarly to $\mathrm{Cl}^{-}$evolutionin the acid stack, the increase of the flux of cations is proportional to the applied $\mathbf{J}$ values, giving to a lower $\eta$ as $\mathbf{J}$ goes up (see Figure 10 and Table 6). This difference tends to disappear when increasing $\mathrm{J}$ and thus the decrease of $\eta$ is slower at higher $\mathrm{J}$ values. Final concentrations of $\mathrm{Cl}^{-}$in the base stack at the different current densities varied from $3.9 \cdot 10^{-3} \mathrm{~mol} \cdot \mathrm{L}^{-1}$ to $9.7 \cdot 10^{-3} \mathrm{~mol} \cdot \mathrm{L}^{-1}$. Figure 10 shows the results of $\eta$ for the base stack at different $\mathrm{J}$ values, which is between $66 \%$ and $90 \%$. This $\eta$ is more stable versus time (Figure $10 \mathrm{~b}$ ) than in case of the acid stack (Figure $8 \mathrm{~b}$ )). The $\eta$ values reported in this work in the base stack are very similar to the ones reported in the literature $\left(38-88 \%\right.$ for $150-900 \mathrm{~A} \cdot \mathrm{m}^{-2}[16], 70-77 \%$

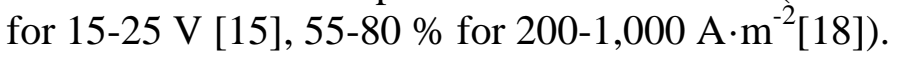

If the performance of EDBM in base and acid production is compared in terms of $\eta$, it can be stated that it is slightly higher for the base than for the acid (66-90\% for the base and $56-85 \%$ for the acid). This is due to a higher $\mathrm{Na}^{+}$flux in the base stack $\left(2.7 \mathrm{~mol} \cdot \mathrm{h}^{-}\right.$ ${ }^{1} \cdot \mathrm{m}^{-2}, 3.7 \mathrm{~mol} \cdot \mathrm{h}^{-1} \cdot \mathrm{m}^{-2}, 7.6 \mathrm{~mol} \cdot \mathrm{h}^{-1} \cdot \mathrm{m}^{-2}, 13.4 \mathrm{~mol} \cdot \mathrm{h}^{-1} \cdot \mathrm{m}^{-2}$ and $18.5 \mathrm{~mol} \cdot \mathrm{h}^{-1} \cdot \mathrm{m}^{-2}$ at $80 \mathrm{~A} \cdot \mathrm{m}^{-}$ ${ }^{2}, 120 \mathrm{~A} \cdot \mathrm{m}^{-2}, 250 \mathrm{~A} \cdot \mathrm{m}^{-2}, 500 \mathrm{~A} \cdot \mathrm{m}^{-2}$ and $750 \mathrm{~A} \cdot \mathrm{m}^{-2}$ respectively) than the $\mathrm{Cl}^{-}$flux in the acid stack $\left(2.5 \mathrm{~mol} \cdot \mathrm{h}^{-1} \cdot \mathrm{m}^{-2}, 3.1 \mathrm{~mol} \cdot \mathrm{h}^{-1} \cdot \mathrm{m}^{-2}, 5.7 \mathrm{~mol} \cdot \mathrm{h}^{-1} \cdot \mathrm{m}^{-2}, 11.9 \mathrm{~mol} \cdot \mathrm{h}^{-1} \cdot \mathrm{m}^{-2}, 15.7\right.$ $\mathrm{mol} \cdot \mathrm{h}^{-1} \cdot \mathrm{m}^{-2}$ for $80 \mathrm{~A} \cdot \mathrm{m}^{-2}, 120 \mathrm{~A} \cdot \mathrm{m}^{-2}, 250 \mathrm{~A} \cdot \mathrm{m}^{-2}, 500 \mathrm{~A} \cdot \mathrm{m}^{-2}$ and $750 \mathrm{~A} \cdot \mathrm{m}^{-2}$ respectively) and thus, a better performance of CEM. This could be due to a higher ion exchange capacity of the CEM [18] and the facilitated transport of co-ions observed in this work in the case of AEM (see Table 5 and Table 6). Although the $\eta$ values are slightly higher for the base, the total drop of $\eta$ when increasing the $\mathrm{J}$ is very similar (24\% for the base versus $29 \%$ for the acid). Consequently the $\eta$ values are influenced by the leakages of $\mathrm{OH}^{-}$in the base stack and $\mathrm{H}^{+}$in the acid stack (4\%-30\% for the base (estimated from Table 6) and $8 \%-35 \%$ for the acid). 

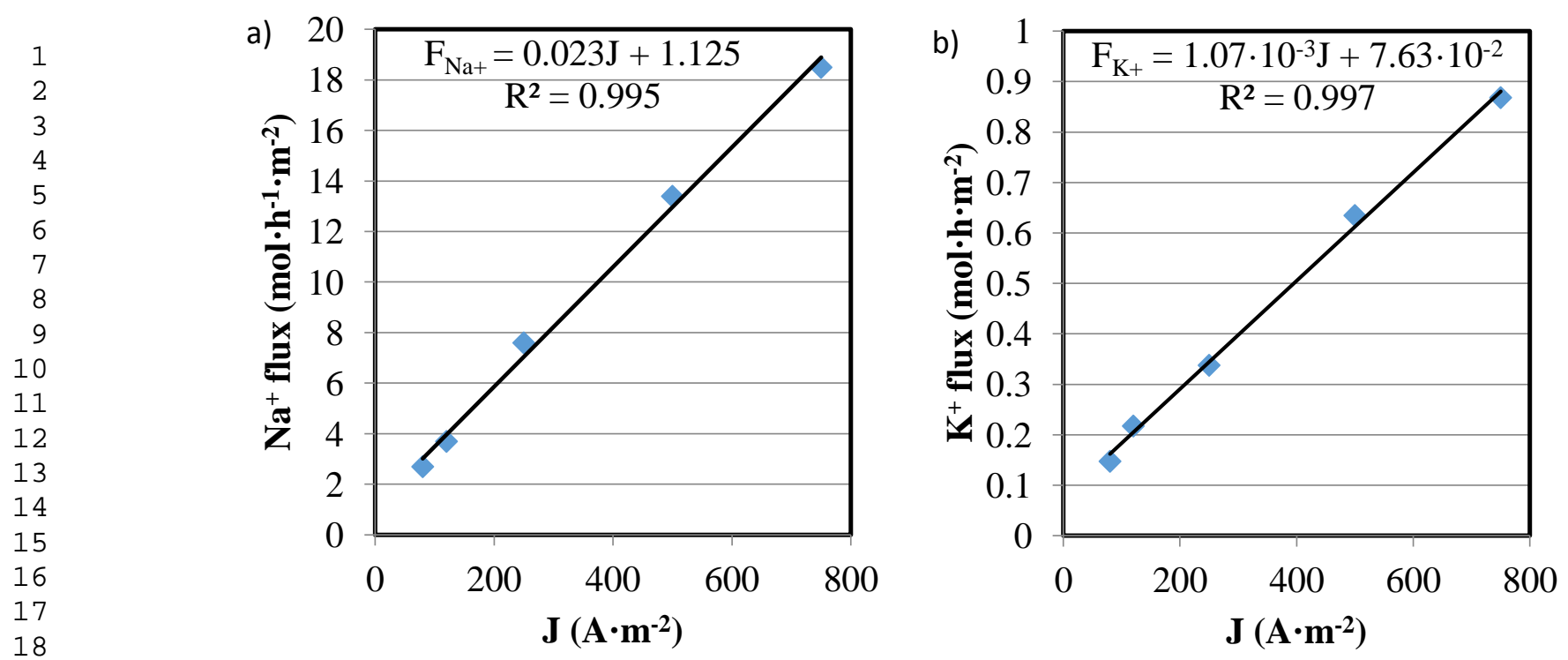

Figure 9. Evolution of flux of a) $\mathrm{Na}^{+}$and b) $\mathrm{K}^{+}$in the base stack versus the $\mathrm{J}$ values in this work using commercial membranes. 

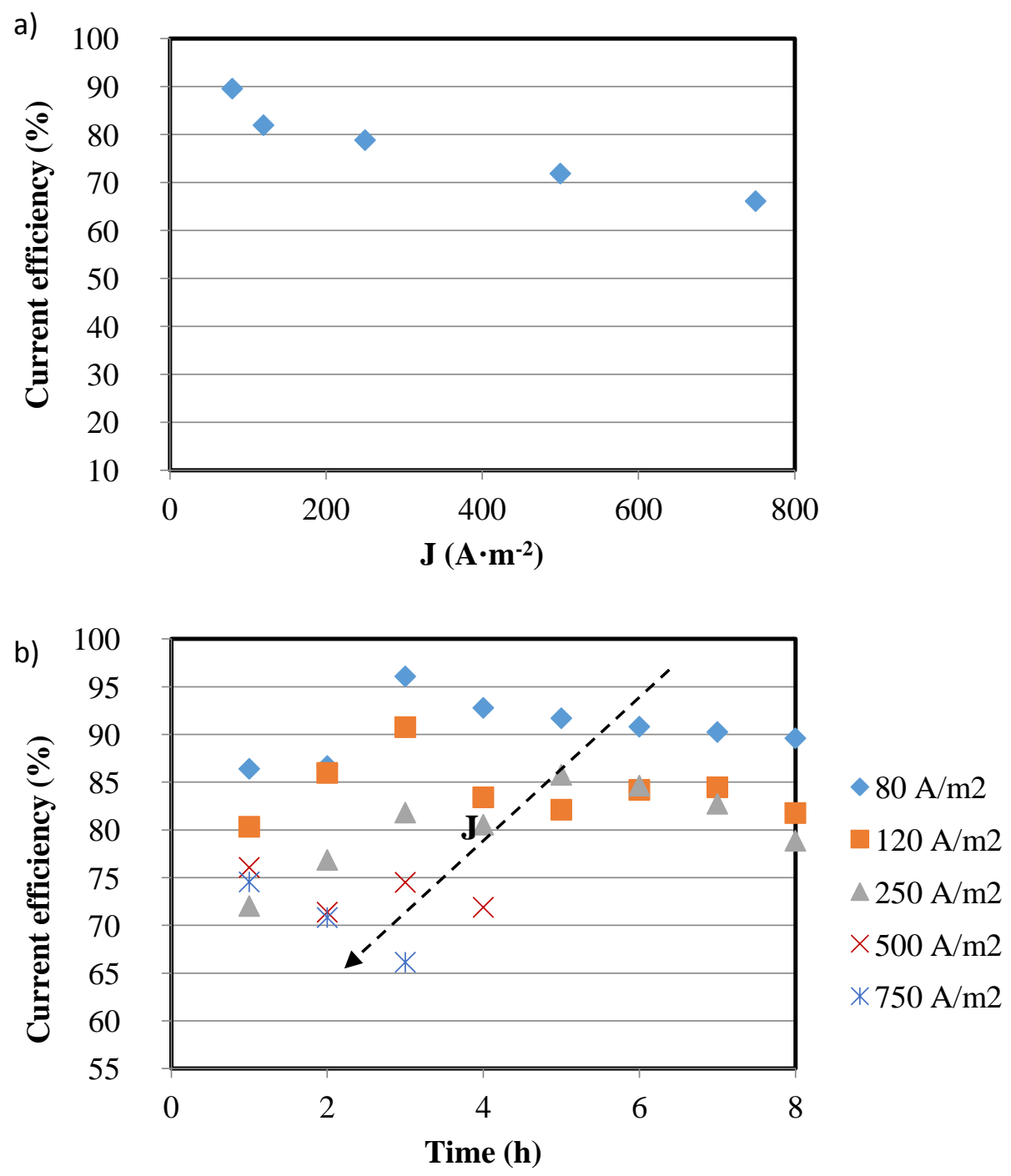

Figure 10. Evolution of $\eta$ with a) time b) J using the membrane AM-0.4NP in the base stack.

Table 6. Fraction of the $\eta$ for the different ions after applying different $\mathrm{J}$ values in the base stack. Results expressed as percentage by means of Eq. 3 .

\begin{tabular}{ccccc}
\hline \multicolumn{5}{c}{$\boldsymbol{\eta}$} \\
\hline $\begin{array}{c}\mathbf{J} \\
\left(\mathbf{A} \cdot \mathbf{m}^{-\mathbf{2}}\right)\end{array}$ & $\begin{array}{c}\mathbf{N a}^{+} \\
(\boldsymbol{\%})\end{array}$ & $\begin{array}{c}\mathbf{K}^{+} \\
(\boldsymbol{\%})\end{array}$ & $\begin{array}{c}\mathbf{C l}^{-} \\
(\boldsymbol{\%})\end{array}$ & $\begin{array}{c}\text { Total } \\
(\boldsymbol{\%})\end{array}$ \\
\hline $\mathbf{8 0}$ & 89.62 & 5.03 & 0.89 & 95.54 \\
$\mathbf{1 2 0}$ & 81.99 & 4.92 & 1.34 & 88.24 \\
$\mathbf{2 5 0}$ & 78.88 & 3.64 & 0.93 & 83.45 \\
$\mathbf{5 0 0}$ & 71.91 & 3.42 & 0.61 & 75.94 \\
$\mathbf{7 5 0}$ & 66.15 & 3.08 & 0.47 & 69.70 \\
\hline
\end{tabular}




\subsection{Stability of nanocomposite membranes}

The stability of the nanocomposite membranes has been evaluated in two ways. First, the existence of the negatively charged layer after 3 cycles of operation in EDBM (93 hours of operation in total) was confirmed using FTIR. Then, their functionality was checked by doing permselectivity experiments after finishing each of the 3 cycles of 31 hours of operation. The nanocomposite membrane AM- $0.4 \mathrm{NP}$, the one with more promising properties according to Table 1 (best monovalent selectivity, lower water contact angle and best fouling resistance), was chosen as a reference for the evaluation of the stability of the nanocomposite membranes used in this work.

Figure 11 includes the FTIR spectrum of commercial AEM AM-PP (Figure 11 a)), nanocomposite membrane AM-0.4NP before operation in EDBM (Figure $11 \mathrm{~b}$ )) and nanocomposite membrane AM-0.4NP after 93 hours of operation in EDBM (Figure 11 c)). In this figure it can be seen that the spectrum of the commercial AEM and the nanocomposite membrane is totally different. In the case of the commercial AEM, two characteristic peaks of $\mathrm{C}-\mathrm{H}$ stretch in $-\mathrm{CH}_{2}-$ and $\mathrm{CH}_{3}-$ substitutes can be seen at 2917 $\mathrm{cm}^{-1}$ and $2849 \mathrm{~cm}^{-1}$ respectively [33]. These peaks correspond to the two main components of the AM-PP membranes, polyethylene and polypropylene. However, in the case of the membranes AM-0.4NP (Figure $11 \mathrm{~b}$ ) and c)) the transmittance bands observed at $1173 \mathrm{~cm}^{-1}, 1061 \mathrm{~cm}^{-1}$ and $1394 \mathrm{~cm}^{-1}$ correspond to the $\mathrm{C}-\mathrm{O}-\mathrm{C}$ stretch of the sPPO, $-\mathrm{SO}_{3} \mathrm{H}$ substitute in the aromatic ring of $\mathrm{PPO}$ and $\mathrm{S}=\mathrm{O}$ stretch of the $\mathrm{SO}_{4}{ }^{2-}$ attached to iron oxide nanoparticles respectively [22,33]. This confirms the existence of the layer of sPPO and $\mathrm{Fe}_{2} \mathrm{O}_{3}-\mathrm{SO}_{4}{ }^{2-}$ nanoparticles in the membrane AM-0.4NP before and after 93 hours of operation in EDBM.

Regarding the functionality of the nanocomposite membranes, Figure 12 includes the evolution of the monovalent selectivity of the membrane AM-0.4NP with operation time in EDBM. The monovalent selectivity remained unmodified, even after 93 hours of operation in EDBM. Thus, from the results presented in Figure 11 and Figure 12 it can be concluded that the negative layer on the surface of the nanocomposite AEM is very stable and the functionality of the membranes AM-0.4NP has not been deteriorated by the operation in EDBM.

Other studies have recently reported good stability of a negatively charged layer on the surface of commercial AEM [34]. However, in this previous work the stability of the membrane was evaluated by measuring its antifouling performance after storage of the membranes in deionized water for some time. In the case of this work, we evaluate the stability of the coating in the very much demanding environment. Additionally, regarding the conventional storage of the membranes, due to the number of tests that have been performed, first characterization and then operation in an EDBM stack, the nanocomposite membranes have been storage in $\mathrm{NaCl} 0.5 \mathrm{~mol} \cdot \mathrm{L}^{-1}$ solution for almost a year. No significant change in performance in terms of monovalent selectivity has been observed since its synthesis, even after starting to operate in acid and base generation by EDBM. Thus, these nanocomposite membranes are very stable and suitable for operation in EDBM. These results also suggest a very promising stability and long lifetime when working in regular ED operation for desalination of water. Additionally, the good stability working with hydrochloric acid showed in this study can be of interest as a good resistance regarding the chemical cleaning that is usually performed in desalination processes [21]. 


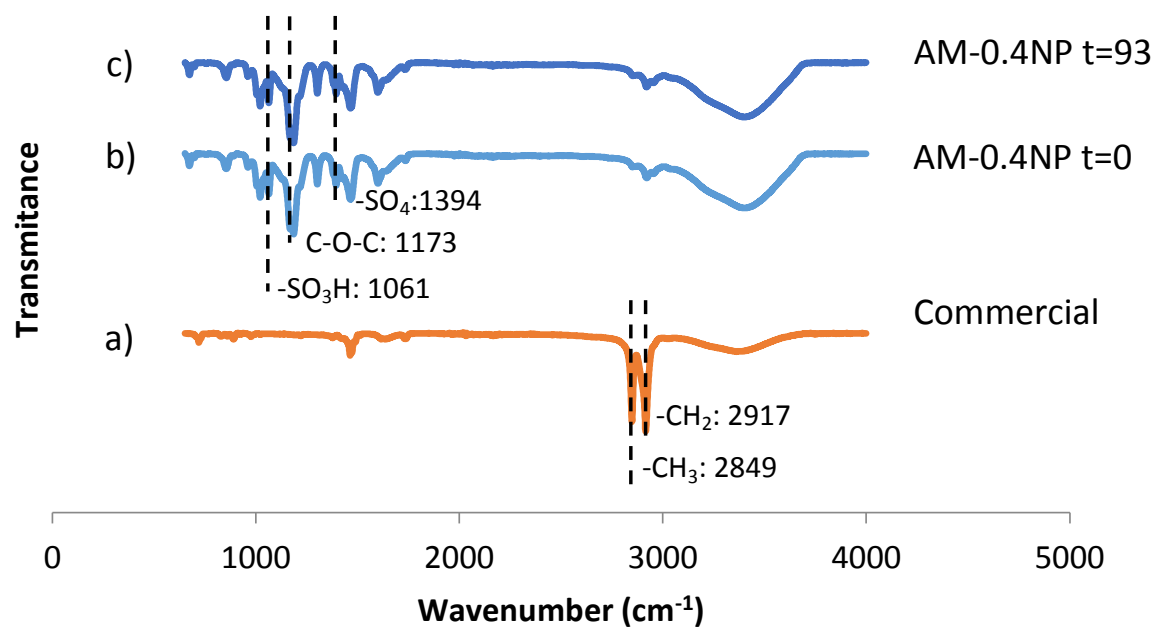

Figure 11. FTIR spectra of anion exchange membranes a) RALEX AM-PP, b) AM$\left.0.4 \mathrm{NP} \mathrm{t}_{\text {operation }} \mathrm{EDBM}=0, \mathrm{c}\right) \mathrm{AM}-0.4 \mathrm{NP} \mathrm{t}_{\text {operation } \mathrm{EDBM}}=93$ hours.

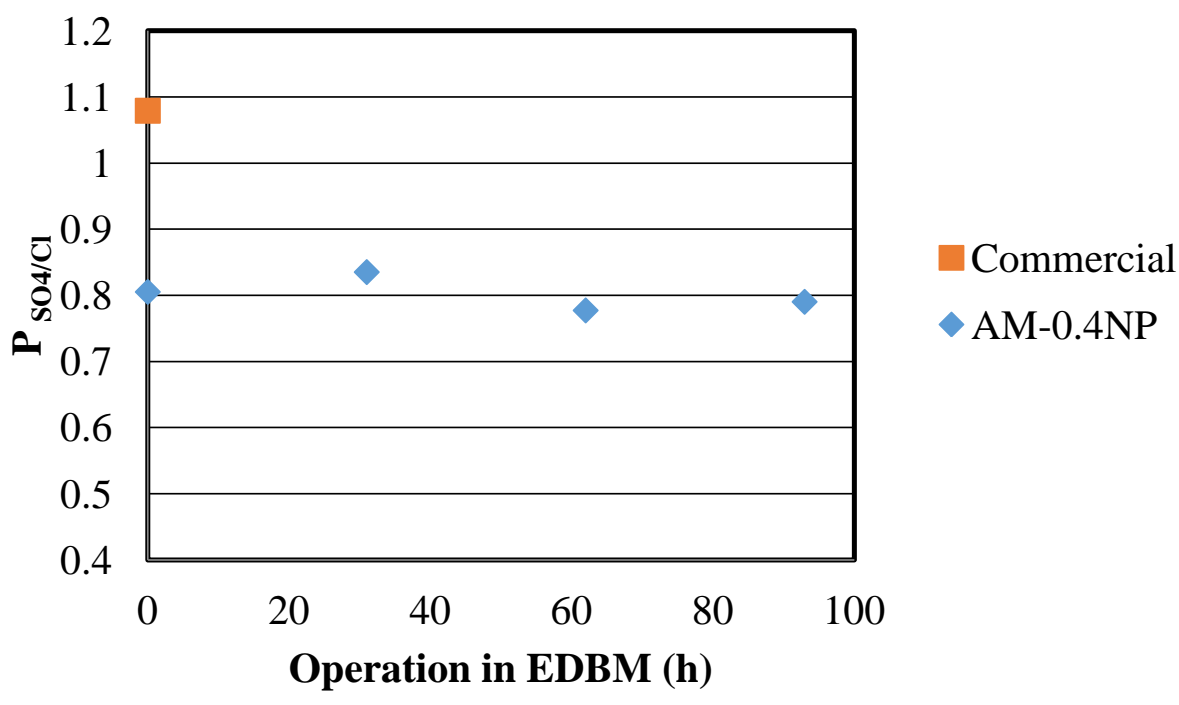

Figure 12. Evolution of monovalent selectivity of the membrane AM- $0.4 \mathrm{NP}$ versus operation time in EDBM.

\section{Conclusions}

EDBM has not developed its full potential for the valorization of desalination brines yet. This work addresses one of the most important remaining challenges, which is the increase of the quality of the obtained acids and bases. A reduction of $10 \%$ in the $\mathrm{SO}_{4}{ }^{2-}$ concentration in the acid stack was achieved using nanocomposite AEM under the experimental conditions of this work. These membranes were synthesized by direct coating of a commercial polyethylene AEM with a negatively charged layer made of sPPO and different loads of functionalized iron oxide nanoparticles. An in-depth analysis of the evolution of the main components and impurities in the acid and the base 
stack was performed. The evolution of $\mathrm{Cl}^{-}, \mathrm{SO}_{4}{ }^{2-}$ and $\mathrm{H}^{+}$in the acid stack was found to be linear versus time. The $\mathrm{Cl}^{-}$and $\mathrm{SO}_{4}{ }^{2-}$ fluxes increased linearly when the current density did. In the case of $\mathrm{Cl}^{-}$, the effect of current density in the flux showed a linear relationship with non-zero intercept. Similar trends for $\mathrm{Na}^{+}, \mathrm{K}^{+}$and $\mathrm{OH}^{-}$were observed in the base stack. The current efficiency was found to be slightly higher for the base stack (66-90\%) than for the acid stack (56-85\%). A similar decrease on current efficiency was observed in both stacks due to proton and hydroxyl ion leakages, being the current utilization associated to these leakages $8-35 \%$ for $\mathrm{H}^{+}$in the acid stack and 4$30 \%$ for $\mathrm{OH}^{-}$the base stack. The nanocomposite membranes showed a good stability when working with acid and bases as their monovalent selectivity remained unchanged after 31, 62 and 93 hours of operation in EDBM. The stability of the nanocomposite membrane AM-0.4NP was also confirmed by the FTIR spectrum. Thus these membranes, which allow a better quality in the produced acid, are suitable for operation in EDBM and valorization of brines into acids and bases. The stability of the nanocomposite membranes at longer operation times and a techno-economic analysis regarding the sustainability of their use in EDBM should be performed.

\section{Acknowledgments}

Financial support from MICINN under project 2014-57833-R and CTQ2013-48280-C31-R-D is gratefully acknowledged. The author thanks the Ministry of Education for FPI grant BES-2012-053461 and the scholarship EEBB-I-15-10268 for the stay at the Georgia Institute of Technology. In addition, this research was partially supported by the U.S. National Science Foundation CBET-1235166.

\section{References}

[1] C. Fernandez-Gonzalez, A. Dominguez-Ramos, R. Ibañez, and A. Irabien. Sustainability assessment of electrodialysis powered by photovoltaic solar energy for freshwater production. Renew Sust Energ Rev, 47 (2015) 604-615.

[2] N. Ghaffour, J. Bundschuh, H. Mahmoudi, and M.F.A. Goosen. Renewable energydriven desalination technologies: A comprehensive review on challenges and potential applications of integrated systems. Desalination, 356 (2015) 94-114.

[3] A. Al-Karaghouli, L.L. Kazmerski. Energy consumption and water production cost of conventional and renewable-energy-powered desalination processes. Renew Sust Energ Rev, 24 (2013) 343-356.

[4] S. Sethi, S. Walker, J. Drewes, and P. Xu. Existing and emerging concentrate minimization and disposal practices for membrane systems. Fla Water Resour J, 58 (2006) 38-48.

[5] A. Pérez-González, A.M. Urtiaga, R. Ibáñez, and I. Ortiz. State of the art and review on the treatment technologies of water reverse osmosis concentrates. Water Res, 46 (2012) 267-283. 
[6] V.G. Gude. Desalination and sustainability - An appraisal and current perspective. Water Res, 89 (2016) 87-106.

[7] N. Ahmad, R.E. Baddour. A review of sources, effects, disposal methods, and regulations of brine into marine environments. Ocean Coast.Manage., 87 (2014) 1-7.

[8] M.C. Mickley, Review of concentrate management options, The Future of Desalination in Texas, Texas Water Development Boards (Ed.), 2004.

[9] E. Korngold, L. Aronov, and N. Daltrophe. Electrodialysis of brine solutions discharged from an RO plant. Desalination, 242 (2009) 215-227.

[10] C. Jiang, Y. Wang, Z. Zhang, and T. Xu. Electrodialysis of concentrated brine from RO plant to produce coarse salt and freshwater. J Membrane Sci, 450 (2014) 323-330.

[11] Y. Zhang, K. Ghyselbrecht, B. Meesschaert, L. Pinoy, and B. Van der Bruggen. Electrodialysis on RO concentrate to improve water recovery in wastewater reclamation. J Membrane Sci, 378 (2011) 101-110.

[12] S. Koter, A. Warszawski. A new model for characterization of bipolar membrane electrodialysis of brine. Desalination, 198 (2006) 111-123.

[13] M.P. Mier, R. Ibañez, and I. Ortiz. Influence of ion concentration on the kinetics of electrodialysis with bipolar membranes. Sep Purif Technol, 59 (2008) 197-205.

[14] V. Mavrov, H. Chmiel, B. Heitele, and F. Rögener. Desalination of surface water to industrial water with lower impact on the environment: Part 4: Treatment of effluents from water desalination stages for reuse and balance of the new technological concept for water desalination. Desalination, 124 (1999) 205-216.

[15] M. Wang, K. Wang, Y. Jia, and Q. Ren. The reclamation of brine generated from desalination process by bipolar membrane electrodialysis. J Membrane Sci, 452 (2014) 54-61.

[16] M. Badruzzaman, J. Oppenheimer, S. Adham, and M. Kumar. Innovative beneficial reuse of reverse osmosis concentrate using bipolar membrane electrodialysis and electrochlorination processes. J Membrane Sci, 326 (2009) 392-399.

[17] J.R. Davis, Y. Chen, J.C. Baygents, and J. Farrell. Production of Acids and Bases for Ion Exchange Regeneration from Dilute Salt Solutions Using Bipolar Membrane Electrodialysis. ACS Sustainable Chem.Eng., 3 (2015) 2337-2342.

[18] R. Ibáñez, A. Pérez-González, P. Gómez, A.M. Urtiaga, and I. Ortiz. Acid and base recovery from softened reverse osmosis (RO) brines. Experimental assessment using model concentrates. Desalination, 309 (2013) 165-170.

[19] Y. Yang, X. Gao, A. Fan, L. Fu, and C. Gao. An innovative beneficial reuse of seawater concentrate using bipolar membrane electrodialysis. J Membrane Sci, 449 (2014) 119-126. 
[20] M. Reig, S. Casas, O. Gibert, C. Valderrama, and J.L. Cortina. Integration of nanofiltration and bipolar electrodialysis for valorization of seawater desalination brines: Production of drinking and waste water treatment chemicals. Desalination, 382 (2016) 13-20.

[21] C. Fernandez-Gonzalez, A. Dominguez-Ramos, R. Ibañez, and A. Irabien. Electrodialysis with bipolar membranes for valorization of brines. Separation and Purification Reviews, 45 (2016) 275-287.

[22] J.G. Hong, Y. Chen. Nanocomposite reverse electrodialysis (RED) ion-exchange membranes for salinity gradient power generation. J.Membr.Sci., 460 (2014) 139-147.

[23] J. Gi Hong, Y. Chen. Evaluation of electrochemical properties and reverse electrodialysis performance for porous cation exchange membranes with sulfatefunctionalized iron oxide. J.Membr.Sci., 473 (2015) 210-217.

[24] S. Mulyati, R. Takagi, A. Fujii, Y. Ohmukai, and H. Matsuyama. Simultaneous improvement of the monovalent anion selectivity and antifouling properties of an anion exchange membrane in an electrodialysis process, using polyelectrolyte multilayer deposition. J Membrane Sci, 431 (2013) 113-120.

[25] T. Sata. Studies on anion exchange membranes having permselectivity for specific anions in electrodialysis - effect of hydrophilicity of anion exchange membranes on permselectivity of anions. J.Membr.Sci., 167 (2000) 1-31.

[26] R. Takagi, M. Vaselbehagh, and H. Matsuyama. Theoretical study of the permselectivity of an anion exchange membrane in electrodialysis. J.Membr.Sci., 470 (2014) 486-493.

[27] T. Sata, Y. Tagami, and K. Matsusaki. Transport properties of anion-exchange membranes having a hydrophobic layer on their surface in electrodialysis. J Phys Chem B, 102 (1998) 8473-8479.

[28] E. Güler, W. van Baak, M. Saakes, and K. Nijmeijer. Monovalent-ion-selective membranes for reverse electrodialysis. J.Membr.Sci., 455 (2014) 254-270.

[29] M. Wang, X.-. Wang, Y.-. Jia, and X. Liu. An attempt for improving electrodialytic transport properties of a heterogeneous anion exchange membrane. Desalination, 351 (2014) 163-170.

[30] T. Sata, K. Mine, and M. Higa. Change in permselectivity between sulfate and chloride ions through anion exchange membrane with hydrophilicity of the membrane. J.Membr.Sci., 141 (1998) 137-144.

[31] T. Sata, T. Yamaguchi, K. Kawamura, and K. Matsusaki. Transport numbers of various anions relative to chloride ions in modified anion-exchange membranes during electrodialysis. Journal of the Chemical Society - Faraday Transactions, 93 (1997) 457462. 
[32] S. Mazrou, H. Kerdjoudj, A.T. Chérif, and J. Molénat. Sodium hydroxide and hydrochloric acid generation from sodium chloride and rock salt by electroelectrodialysis. J.Appl.Electrochem., 27 (1997) 558-567.

[33] B.D. Mistry, A handbook of spectroscopic data, Chemistry (UV, IR, PMR, CNMR and MAss Spectroscopy), , Oxford book company, ISBN: 987-81-89473-86-0, 2009.

[34] M. Vaselbehagh, H. Karkhanechi, S. Mulyati, R. Takagi, and H. Matsuyama. Improved antifouling of anion-exchange membrane by polydopamine coating in electrodialysis process. Desalination, 332 (2014) 126-133. 
Polyethylene based anion exchange membrane

\section{Desalination} Brine

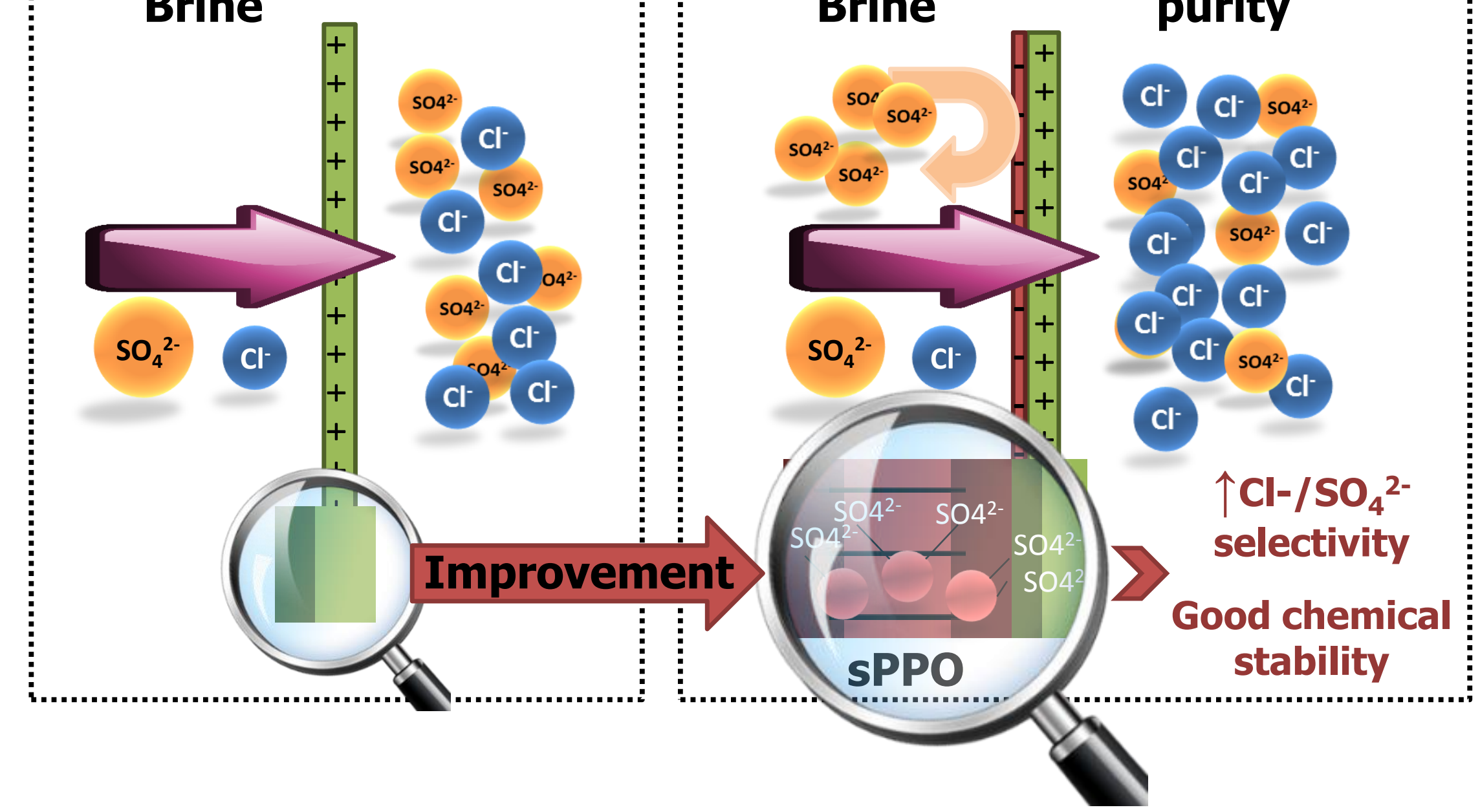

Nanocomposite anion exchange membrane

Desalination $\mathrm{HCl}$ of Higher Brine

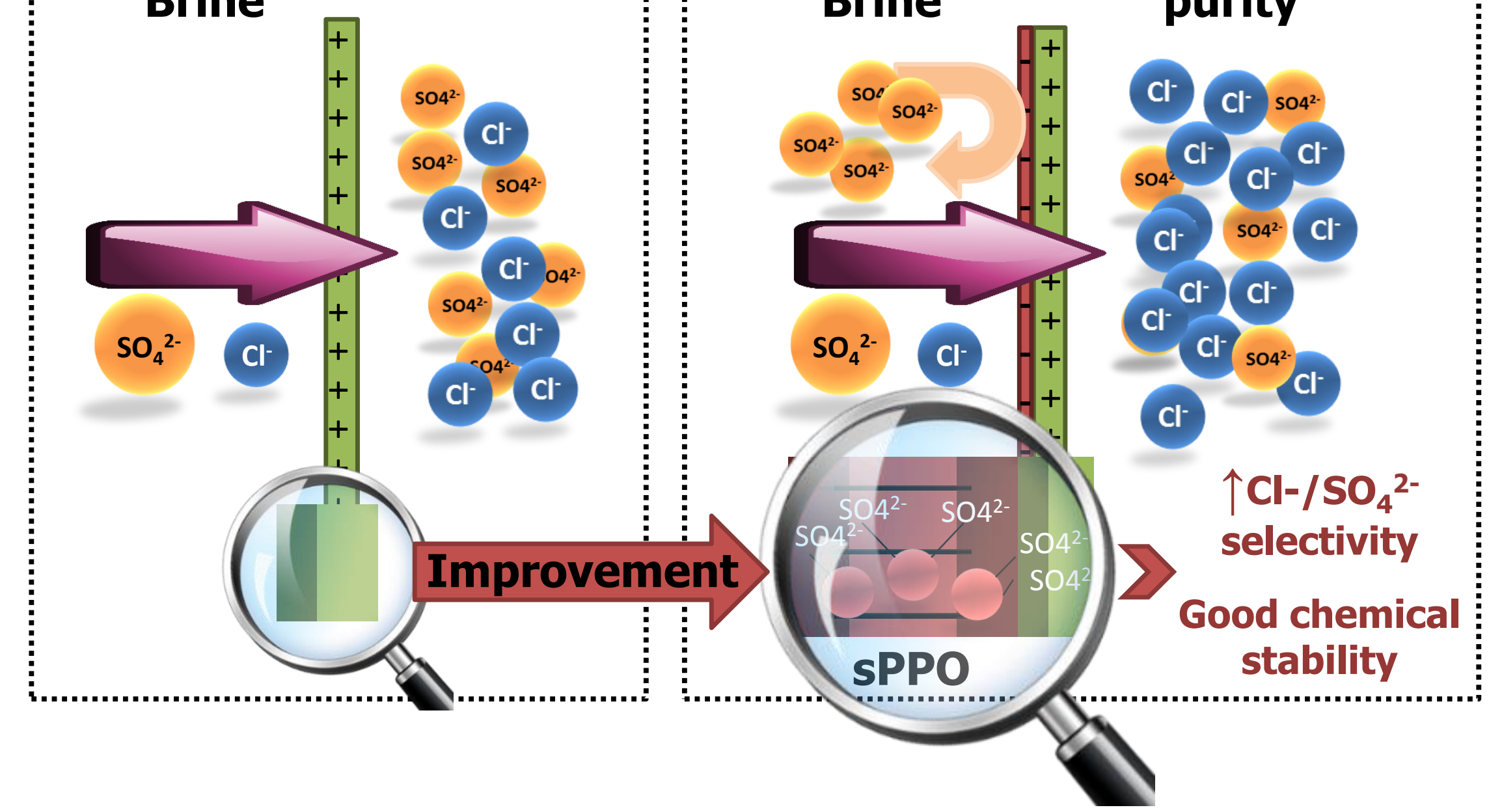

